\title{
A Randomized Controlled Trial of Caries Prevention in Dental Practice
}

DOI:

$10.1177 / 0022034517702330$

\section{Document Version}

Accepted author manuscript

Link to publication record in Manchester Research Explorer

\section{Citation for published version (APA):}

Tickle, M., O'Neill, C., Donaldson, M. ., Birch, S., Noble, S., Killough, S., Murphy, L., Greer, M., Brodison, J., Verghis, R., \& Worthington, H. (2017). A Randomized Controlled Trial of Caries Prevention in Dental Practice. Journal of Dental Research, 96(7), 741-746. https://doi.org/10.1177/0022034517702330

\section{Published in:}

Journal of Dental Research

\section{Citing this paper}

Please note that where the full-text provided on Manchester Research Explorer is the Author Accepted Manuscript or Proof version this may differ from the final Published version. If citing, it is advised that you check and use the publisher's definitive version.

\section{General rights}

Copyright and moral rights for the publications made accessible in the Research Explorer are retained by the authors and/or other copyright owners and it is a condition of accessing publications that users recognise and abide by the legal requirements associated with these rights.

\section{Takedown policy}

If you believe that this document breaches copyright please refer to the University of Manchester's Takedown Procedures [http://man.ac.uk/04Y6Bo] or contact uml.scholarlycommunications@manchester.ac.uk providing relevant details, so we can investigate your claim.

\section{OPEN ACCESS}




\section{Journal of \\ Dental Research}

\section{A randomized controlled trial of caries prevention in dental practice}

\begin{tabular}{|c|c|}
\hline Journal: & Journal of Dental Research \\
\hline Manuscript ID & JDR-16-1195.R1 \\
\hline Manuscript Type: & Research Reports \\
\hline Date Submitted by the Author: & 15-Feb-2017 \\
\hline Complete List of Authors: & $\begin{array}{l}\text { Tickle, Martin; The University of Manchester, Division of Dentistry, School } \\
\text { of Medical Sciences } \\
\text { O'Neill, Ciaran; Queen's University Belfast, Centre for Public Health } \\
\text { Donaldson, Michael; Health and Social Care Board } \\
\text { Birch, Stephen; The University of Manchester, School of Medical Sciences } \\
\text { Noble, Solveig; Braid Valley Hospital, Community Dental Department } \\
\text { Killough, Seamus; British Dental Association Northern Ireland, The Mount } \\
\text { Business Centre } \\
\text { Murphy, Lynn; Belfast Health and Social Care Trust, Northern Ireland } \\
\text { Clinical Trials Unit } \\
\text { Greer, Margaret; hVIVO, Queen Mary BioEnterprises Innovation Centre } \\
\text { Brodison, Julie; DJ Maguire and Associates } \\
\text { Verghis, Rejina; Belfast Health and Social Care Trust, Northern Ireland } \\
\text { Clinical Trials Unit } \\
\text { Worthington, Helen; The University of Manchester, Division of Dentistry, } \\
\text { School of Medical Sciences }\end{array}$ \\
\hline Keywords: & $\begin{array}{l}\text { Child Dentistry, Clinical studies/trials, Comparative effectiveness research } \\
\text { (CER), Fluoride(s), Health services research, Evidence-based } \\
\text { dentistry/health care }\end{array}$ \\
\hline Abstract: & $\begin{array}{l}\text { Background: We conducted a parallel group randomised controlled trial of } \\
\text { children initially aged } 2-3 \text { years who were caries free, to prevent the } \\
\text { children becoming caries active over the subsequent } 36 \text { months. } \\
\\
\text { Methods: The setting was } 22 \text { dental practices in Northern Ireland and } \\
\text { children were randomly assigned by a Clinical Trials Unit (using computer } \\
\text { generated random numbers, with allocation concealed from the dental } \\
\text { practice until child was recruited) to the intervention ( } 22,600 \text { ppm fluoride } \\
\text { varnish, toothbrush, } 50 \mathrm{ml} \text { tube of } 1,450 \text { ppm fluoride toothpaste and } \\
\text { standardised, evidence-based prevention advice), or advice-only control, at } \\
6 \text {-monthly intervals. The primary outcome measure was conversion from } \\
\text { caries-free to caries-active states. Secondary outcome measures were } \\
\text { dmfs in caries active children, number of episodes of pain, number of } \\
\text { extracted teeth. Adverse reactions were recorded. Calibrated external } \\
\text { examiners, blinded to the child's study group, assessed the status of the } \\
\text { children at baseline and after } 3 \text { years. }\end{array}$ \\
\hline
\end{tabular}


Results: 1248 children (624 randomised to each group) were recruited and 1,096 (549 intervention, 547 control) were included in the final analyses. $87 \%$ of intervention and $86 \%$ of control children attended every 6 -month visit $(P=0.77) .187(34 \%)$ of intervention group converted to caries-active compared to $213(39 \%)$ in control (OR $0.81,95 \%$ CI 0.64 to 1.04 ;

$\mathrm{P}=0.11$ ). Mean $\mathrm{dmfs}$ of those with caries in intervention group was 7.2 compared to 9.6 in control group $(P=0.007)$. There was no significant difference in the number of episodes of pain between groups, $(P=0.81)$ or in the number of teeth extracted in caries-active children $(P=0.95)$. Ten children in the intervention group had adverse reactions of a minor nature.

Conclusion: This well conducted trial failed to demonstrate that the intervention kept children caries free, however there was evidence that once children get caries it slowed down its progression.

Trial registration:

EudraCT No: 2009-010725-39

ISRCTN: ISRCTN36180119

\section{SCHOLARONEm \\ Manuscripts}




\section{Title: A randomized controlled trial of caries prevention in dental practice}

(70 Characters)

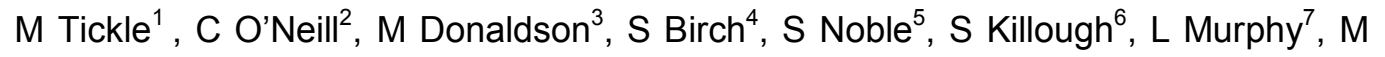

Greer $^{8}$, J Brodison ${ }^{9}$, R Verghis ${ }^{7}$, HV Worthington ${ }^{1}$

1. Division of Dentistry, School of Medical Sciences, Faculty of Biology, Medicine and Health, University of Manchester, UK

2. Centre for Public Health, Queens' University Belfast UK

3. Health \& Social Care Board of Northern Ireland

4. School of Medical Sciences, Faculty of Biology, Medicine and Health, University of Manchester, UK

5. Northern Health \& Social Care Trust, Northern Ireland

6. British Dental Association, Belfast, Northern Ireland

7. Northern Ireland Clinical Trials Unit, Belfast Health \& Social Care Trust, Northern Ireland

8. hVIVO, Queen Mary BioEnterprises Innovation Centre, London, UK

9. DJ Maguire and Associates, Portadown, Northern Ireland

Corresponding author: Professor Martin Tickle, University of Manchester email martin.tickle@manchester.ac.uk

Abstract word count (without trial registration details): 290

Total word count (excluding Abstract and acknowledgments): 3200

Total number of tables/figures: 5

Number of references: 20

Key words: Child Dentistry, Clinical studies/trials, Comparative effectiveness research (CER), Fluoride(s), Health services research, Evidence-based dentistry/health care 


\section{ABSTRACT}

Background: We conducted a parallel group randomised controlled trial of children initially aged 2-3 years who were caries free, to prevent the children becoming caries active over the subsequent 36 months.

Methods: The setting was 22 dental practices in Northern Ireland and children were randomly assigned by a Clinical Trials Unit (using computer generated random numbers, with allocation concealed from the dental practice until child was recruited) to the intervention $(22,600 \mathrm{ppm}$ fluoride varnish, toothbrush, $50 \mathrm{ml}$ tube of $1,450 \mathrm{ppm}$ fluoride toothpaste and standardised, evidence-based prevention advice), or adviceonly control, at 6-monthly intervals. The primary outcome measure was conversion from caries-free to caries-active states. Secondary outcome measures were dmfs in caries active children, number of episodes of pain, number of extracted teeth. Adverse reactions were recorded. Calibrated external examiners, blinded to the child's study group, assessed the status of the children at baseline and after 3 years.

Results: 1248 children (624 randomised to each group) were recruited and 1,096 (549 intervention, 547 control) were included in the final analyses. $87 \%$ of intervention and $86 \%$ of control children attended every 6 -month visit $(P=0.77) .187$ (34\%) of intervention group converted to caries-active compared to $213(39 \%)$ in control (OR $0.81,95 \% \mathrm{Cl} 0.64$ to $1.04 ; \mathrm{P}=0.11)$. Mean dmfs of those with caries in intervention group was 7.2 compared to 9.6 in control group $(P=0.007)$. There was no significant difference in the number of episodes of pain between groups, $(P=0.81)$ or in the number of teeth extracted in caries-active children $(P=0.95)$. Ten children in the intervention group had adverse reactions of a minor nature.

Conclusion: This well conducted trial failed to demonstrate that the intervention kept children caries free, however there was evidence that once children get caries it 
slowed down its progression.

Trial registration:

EudraCT No: 2009-010725-39

ISRCTN: ISRCTN36180119

\section{INTRODUCTION}

Dental caries is the commonest disease of childhood; in 2013 a UK national survey reported a prevalence of untreated decay of 28 per cent in England, 39 per cent in Wales and 37 per cent in Northern Ireland among 5-year-old children (Pitts et al. 2015). Caries is closely associated with deprivation and once the disease develops pain and extractions are common consequences (Tickle et al. 2008). Developing the disease in the primary teeth is a strong predictor of developing disease in the permanent teeth (Milsom et al. 2008) and so primary prevention in early childhood is important. Over the last 30 years there has been a shift in emphasis for dental services to focus on prevention (Birch et al. 2015). In the UK, national guidelines on prevention (Public Health England 2014) support this policy objective. For all young children who are caries free, the guidelines recommend application of fluoride varnish twice a year and use of fluoridated toothpaste containing no less than 1,000 parts per million (ppm) fluoride. Although Cochrane systematic reviews (Marinho et al. 2013; Marinho et al. 2004; Marinho et al. 2003) suggest that the fluoride interventions advocated in the guidelines are effective, they have not been tested in a pragmatic trial in a general practice setting. This paper reports the clinical outcomes of a combination fluoride intervention designed to prevent caries developing in young children attending dental services. The trial report has been published in full by the funder (Tickle et al. 2016).

\section{METHODS}


We undertook a randomised, two-arm, parallel group pragmatic trial with an allocation ratio of $1: 1$, in $22 \mathrm{NHS}$ dental practices in Northern Ireland. Trial recruitment took place between May 2011-June 2012; the trial protocol (Tickle et al. 2011) was published and no important changes were made after the trial commencement. We obtained ethical approval from The Greater Manchester Central Research Ethics Committee on 08/07/2009 (REC reference number 09/H1008/93), and a certificate of trial authorization was obtained from the Medicines and Healthcare Products Regulatory Agency.

Inclusion criteria were children aged 2 to 3 but not yet 4 -years-old, caries free (into dentine) and registered with the $22 \mathrm{NHS}$ dental practices recruited into the trial. Children were excluded if they had a past history of fillings or extractions due to caries, fissure sealants on primary molar teeth, andlor a history of severe allergic reactions requiring hospitalisation. Independent dentists from the Community Dental Service (CDS) screened children attending the trial practices according to inclusion and exclusion criteria. The Belfast Clinical Trials Unit (CTU) centrally randomised children into intervention and control groups. A specific computer generated randomisation schedule was prepared by the CTU for each practice, using randomised permutated blocks. The block lengths varied to ensure that the CDS examiners who completed the baseline examinations were blind to patient allocation. The child's dentist or the external CDS dentists obtained parental consent for each child and baseline examinations were undertaken after consent but prior to randomisation.

The intervention consisted:

- $22,600 \mathrm{ppm}$ of fluoride varnish was applied to all primary teeth by their dentist

- a toothbrush and $50 \mathrm{ml}$ tube of $1,450 \mathrm{ppm}$ of fluoride toothpaste. 
The intervention (varnish, toothbrush and toothpaste) was delivered at the child's dental check up, twice a year at approximately 6-month intervals. The control group did not receive any professionally-provided fluoride interventions but both groups received the same standardised dental health advice on optimal use of fluoride toothpaste and restriction of sugar consumption every 6 months at their dental check up (see Appendix).

The follow-up period was three years. Caries outcomes were assessed by 12 trained and calibrated (see appendix table 1) CDS dentists, blind to the allocation, undertaking clinical examinations according to a standardised, national diagnostic protocol (Mitropoulos et al. 1992). The primary outcome measure was conversion from caries-free to caries-active states (diagnosed at the caries into dentine level) and secondary outcome measures included the number of decayed, missing or filled teeth surfaces (dmfs - caries into dentine) in children with caries and the number of episodes of pain and extractions. All serious adverse events and adverse reactions associated with the fluoride varnish were recorded. These outcomes were recorded by parental questionnaires and a data collection form completed by the practices, there were no changes to outcome measures after the trial commenced.

The sample size was based on the expectation of an absolute difference in the proportion of children with caries after 3 years of 0.1 between intervention and control groups. Based on epidemiological (Lader et al. 2005) and dental service data available, it was estimated that 47 per cent of children would develop caries over three years. A two group chi-square test with a 0.05 two-sided significance level would have 90 per cent power to detect the difference between a proportion of 0.47 and a proportion of 0.37 (odds ratio of 0.662 ) if the sample size in each group is 510 . We assumed a $70 \%$ consent rate and a $15 \%$ drop-out rate. Using these assumptions we estimated we would need to invite at least 2356 children to take part in the study 
and recruit 1200 children to ensure we had sufficient power at the end of the trial.

All statistical analyses were performed using Stata using an intention to treat approach with a 2-sided 5 per cent significance level. We followed the Statistical Analysis Plan agreed by the trial's Independent Data Monitoring Committee prior to the analysis of the data. The primary analysis compared the proportion of children in each group who converted from caries free to caries active over the three years using a binary logistic regression model and was adjusted for age and socioeconomic status quintiles categorised using the Multiple Deprivation Measure (MDM) 2010 (Northern Ireland Statistics \& Research Agency 2010), a small area measure derived from the home postcode of participants. We also report two other analyses: firstly an unadjusted analysis, and secondly an analysis adjusting for practice as well as age and MDM 2010 quintile. This analysis used the Huber-White approach within Stata (vce(cluster)) to deal with potential practice clustering effects (also known as sandwich estimator and robust estimator of variance).

The number of episodes of pain for each patient were compared between treatment groups using a negative binomial model adjusting for age, MDM and for whether the child was caries active or not as the primary analyses (age, MDM). As it was difficult to determine single discrete episodes of pain (which went up to 17 episodes) this was capped for each child at a maximum of 6 over the 36-month period (this affected the pain scores of 8 children). The number of teeth extracted for each patient who converted from caries free to caries active was compared between treatment groups using a negative binomial model adjusting for the same covariates as the primary analysis (age, MDM).

\section{RESULTS}


2455 children were screened by CDS dentists according to the trial inclusion and exclusion criteria, and 1248 (624 per group) were recruited into the trial, exceeding the planned sample size of 1200 (Figure 1). At the 3-year follow up examination 1,096 children; 549 in the intervention and 547 in the control group, were examined for caries, which exceeded the 510 per group specified in the sample size calculation. Outcome examinations were completed in July 2015 and the trial was closed in September 2015 as scheduled. There were only a small number of withdrawals during the trial: 46 in the intervention group and 45 in the control group, a further 61 children were not examined at the final assessment. The reasons for withdrawals were: dentist withdrew child due to failure to attend and child uncooperative (number in intervention group 22; number in control 17), moved to another practice $(14 ; 15)$, moved out of area $(5 ; 5)$, enrolled in error (caries at baseline, sibling in study, wrong age) $(1 ; 2)$, child did not want to participate $(1 ; 0)$, parent withdrew child $(3 ; 5)$, child referred to $\operatorname{CDS}(0 ; 1)$. Dentists were withdrawing children due to failure to attend, as they were following local practice policies on nonattendance. This was picked up at an early stage and these local policies were stopped for trial children and therefore unlikely to have introduced any bias. Eightyseven per cent of children in the intervention group and 86 per cent of the children in the control group attended every 6 -month scheduled visit to the practice $(P=0.77)$. All of the children in the trial attended at least once. The baseline demographic data are presented in Table 1 and there was excellent balance between the study groups for gender, age, quintile of deprivation and practice (not shown).

\section{Caries active at follow-up and dmfs}

For the primary outcome measure, the number and percentage of children who converted from caries free to caries active was 187 (34\%) in the intervention group compared with $213(39 \%)$ in the control group, this difference was not statistically 
significant (Adjusted Odds Ratio $0.81,95 \% \mathrm{Cl} 0.64$ to $1.04 ; \mathrm{P}=0.11$ ) (Tables 2, 3).

Similar results were found for the unadjusted model and model adjusted for gender, MDM and practice (Table 3).

The secondary outcome was the difference in the mean number of carious surfaces (dmfs) between children with caries in the intervention and control groups (Table 4). The mean number of tooth surfaces affected by caries in the intervention group was 7.2 compared to 9.6 surfaces in the control group. This difference was statistically significant, adjusted mean difference $-2.29 \mathrm{dmfs}(95 \% \mathrm{Cl}-3.96$ to $-0.63 ; \mathrm{P}=0.007)$ (Table 3).

\section{Pain and extracted teeth}

There were differences in the proportion of children with pain and the mean number of episodes per child, between children with and without caries. The regression models therefore included caries status at follow up as a covariate. There was no difference in the number of episodes of pain or proportion of children with toothache between the study groups over the 36 months (OR $0.95(95 \% \mathrm{Cl} 0.69$ to 1.30 ; $\mathrm{P}=0.74$ ) (Table 3). Forty-one per cent of children with caries had toothache compared with 9 per cent of children who were caries free; this difference was statistically significant $(\mathrm{OR} 7.195 \% \mathrm{Cl} 5.1$ to 9.9 ; $\mathrm{P}<0.0001)$. In children with caries the mean numbers of episodes of pain were 0.85 in the intervention group compared with 1.08 in the control (Table 4). For all children the negative binomial model, adjusted for caries status, for the number of episodes of pain, which indicated significant over-dispersion, was also not statistically significant (regression coefficient $-0.0395 \% \mathrm{Cl}(-0.32$ to $0.25 ; \mathrm{P}=0.81)($ Table 3$)$. 
In the intervention group 11.2 per cent of children with caries had teeth extracted over the 3-year period, compared with 13.1 per cent of children with caries in the control group (Table 2), the mean percentage difference being 1.9 per cent $(95 \% \mathrm{Cl}$ $4.5 \%$ to $8.3 \%$ ). A logistic regression model adjusted for age and MDM quintile was not statistically significant $\mathrm{OR} 0.84(95 \% \mathrm{Cl} 0.45$ to $1.54 ; \mathrm{P}=0.56)$. The mean number of extracted teeth was 0.45 in the intervention group compared with 0.46 in the control (Table 4). The negative binomial model for the number of extracted teeth, which indicated significant over-dispersion, was also not statistically significant (regression coefficient $-0.0395 \% \mathrm{Cl}(-0.88$ to $0.82 ; \mathrm{P}=0.95)$ (Table 3$)$.

\section{Adverse Events and Reactions}

Out of the 1248 children who were randomised, 82 children reported 100 adverse reactions or Serious Adverse Events (SAEs); 45 (7.2\%) children in the intervention group and 37 (5.9\%) in the control group (negative binomial regression coefficient (in favour of intervention) $-0.19,95 \% \mathrm{Cl}-0.27$ to $0.65 ; \mathrm{P}=0.42$ ) (Table 3 ). Eighty-five adverse reactions or SAEs were considered to be unrelated, and the remainder unlikely to be related (10 in the intervention group, 5 in the control group). There were no Serious Adverse Reactions or Suspected Unexpected Serious Adverse Reactions (see appendix table 2). We identified a small number of adverse reactions with a possible link to the varnish; all of these were minor in nature and self-limiting which suggests that fluoride varnish in this young age group is safe.

\section{DISCUSSION}

This is the first large-scale trial of caries prevention in a general practice setting. Both arms of the trial exhibited high levels of compliance to the protocol; approximately 87 per cent of children attended every 6 months for 3 years, and a mean of 5.8 varnish applications were provided to children in the intervention group. Despite the excellent 
compliance, 34 per cent of children in the intervention group and 39 per cent in the control group converted from caries-free to caries-active and the 5 per cent difference we found in caries prevalence in favour of the intervention group was not statistically significant. Children who converted to caries active developed a lot of disease rapidly (dmfs: intervention: 7.2 , control: 9.6 ) and the intervention produced a statistically significant difference of 2 surfaces in these children in favour of the intervention. When all children were included in the denominator the intervention produced a statistically significant 34 per cent reduction in dmfs and a 30 per cent reduction in $\mathrm{dmft}$.

The primary outcome measure was unusual; children converting from a 'caries free' state to a 'caries active' state. The choice of primary outcome measure was appropriate for the policy context in the UK. At the time the trial was designed, guidance (Department of Health/BASCD 2007) was sent to every NHS dental practice recommending provision of fluoride varnish twice a year to young children attending dental practice who were caries free, and 3 to 4 times a year to high-risk children. This policy of providing universal prevention to children traditionally perceived as 'low-risk' needed to be evaluated because considerable costs are incurred in delivering this service in a state-funded system. The ambitious aim of the trial, keeping children 'caries free,' is a now a national policy aspiration in England; the Children's Oral Health Improvement Programme Board of Public Health England (Public Health England 2016) has set the ambition that "every child grows up free from tooth decay as part of every child having the best start in life." The importance of keeping young children caries free has also been demonstrated in a recent longitudinal study (Hall-Scullin et al. in press) which showed that children with caries in their primary teeth were nearly five times more likely to develop caries in their permanent teeth than children who had caries-free primary dentition. 
We recognise that diagnosis can be undertaken at many possible points during the development of caries lesions. We did not measure enamel caries, instead we chose caries into dentine as a hard end point, as it has definite clinical and costs consequences for patients, clinicians and policy makers. One could query if the trial was underpowered, as there was a 20 per cent absolute reduction in population caries in Northern Ireland during the conduct of the trial (Ravaghi et al. 2013). The caries prevalence in the control group at the end of the 3-year follow up period was 39 per cent; lower than the 47 per cent anticipated in the protocol (Tickle et al. 2011). We report a non-significant 5 per cent absolute reduction in children developing caries into dentine; however the 10 per cent difference we stipulated was inside the 95 per cent confidence interval for the primary outcome $(-1 \%$ to $11 \%)$. This post hoc assessment demonstrated that the large fall in population caries had no effect on the power of the trial to detect a 10 per cent difference. The trial eligibility criteria and the consent process probably resulted in a trial population that was motivated and dentally aware, which could account for the high compliance rates and lower caries prevalence in the trial population than our a priori estimates. Therefore, like most trials, the external validity of our findings can be called in to question. However, this group of low-risk, regularly attending children is important to dentists, as they make up the majority of children they see in their practices; a UK, practice-based, observational cohort study (Milsom et al. 2008) showed that 84 per cent of young children were caries free at their first visit. Motivated, regularly attending children would traditionally be regarded as low-risk, but 39 per cent of children in the control group developed caries, demonstrating that prevention is important for groups historically viewed as low-risk as well as those viewed as high-risk.

\begin{abstract}
A targeted prevention approach for high-risk groups within a general practice setting is problematic; attendance at dental practice is closely associated with socioeconomic position (Holmes et al. 2016) and children from disadvantaged
\end{abstract}


communities, with a higher risk of developing caries, are unlikely to demonstrate the compliance levels we achieved in the trial. There is also the issue of ensuring dental practices adhere to preventive care guidelines and recommendations. NHS data (Health \& Social Care Information Centre 2015) contemporary with the trial showed that only 32.1 per cent of children attending dental practices received at least one application of fluoride varnish per year. To increase practice compliance rates to the levels we achieved in the trial, we suspect, would require additional financial incentives which would have an impact on the cost-effectiveness of the intervention, the details of which are reported in full elsewhere (O'Neil et al. in press).

Based on the primary outcome, this composite intervention did not produce the large improvements to match the ambitions of national policy (Public Health England 2016). A Cochrane systematic review compared combinations of topical fluoride (toothpastes, mouthrinses, gels, varnishes) with single topical fluoride for preventing dental caries in children and adolescents (Marinho et al. 2004). Few trials were available to assess the effects of combination fluoride interventions on the primary dentition, and no meta analyses were presented. The effect size found in our trial is consistent with the outcomes of the Cochrane fluoride varnish systematic review (Marinho et al. 2013), but without comparable data it is difficult to say whether combining the two fluoride therapies had an additive effect.

The traditional, secondary outcome measures of caries showed that prevention in practice has a role to play in prevention strategies. We demonstrated a 34 per cent statistically significant reduction in dmfs in this population and in those children who developed the disease; it progressed rapidly going from 0 to $9.6 \mathrm{dmfs}$ in the control group within 3 years. The trial showed that the intervention slowed the development of caries in those that converted to caries-active (dmfs: intervention: 7.2, control: 9.6). It is important to test if more frequent exposure to professionally applied 
fluoride, as advocated by national guidance, (Public Health England 2014) would have a greater impact in slowing disease progression. It is also important to see if the intervention affected the disease trajectory of children in the control group by longer term follow up, which we plan to do.

\section{Conclusions}

This well conducted randomised controlled trial investigated whether the preventive intervention could keep young children caries free, which is the preventive step change policy makers in the UK are looking for. The trial had high retention and compliance rates but failed to demonstrate that it did keep children caries free. There is evidence from the trial that once children develop caries the intervention does slow down its progression. The intervention may have greater impact in a population with high caries levels and if it is delivered in different settings such as schools/nurseries.

\section{ACKNOWLEDGEMENTS}

This project was funded by the National Institute for Health Research Health Technology Assessment programme (project number 08/14/19). The views expressed are those of the authors and not necessarily those of the NHS, the NIHR or the Department of Health.

We would like to thank the practice principals and staff of the 22 Dental Practices involved in the trial, CDS Dentists who undertook the baseline and outcome examinations, the Health and Social Care Board of Northern Ireland, the 5 Health and Social Care (HSC) Trusts of Northern Ireland: Belfast HSC Trust, South Eastern HSC Trust, Western HSC Trust, Southern HSC Trust and Northern HSC Trust, the Department of Health, Social Services and Public Safety, former Chief Dental Officer Donncha O'Carolan, Simon Reid Chief Dental Officer, Members of the Trial Steering Group chaired by Professor Donald Burden, Members of the Independent Data Monitoring and Ethics Committee chaired by Professor Jan Clarkson and latterly by Professor Ivor Chestnutt, the staff of The Northern Ireland Clinical Trials Unit and PPI group chaired by Carolyn Slee. 
1

2

3

4

5

6

7

8

9

10

11

12

13

14

15

16

17

18

19

20

21

22

23

24

25

26

27

28

29

30

31

32

33

34

35

36

37

38

39

40

41

42

43

44

45

46

47

48

49

50

51

52

53

54

55

56

57

58

59

60

Martin Tickle reports provision of free toothpaste and toothbrushes from Colgate-Palmolive for the trial. Seamus Killough was chairperson of the Northern Ireland Council of the British Dental Association throughout this trial.

The other authors have no known conflicts of interest 


\section{References}

Birch S, Bridgman C, Brocklehurst P, Ellwood R, Gomez J, Helgeson M, Ismail A, Macey R, Mariotti A, Twetmen $S$ et al. 2015. Prevention in practice - a summary. BMC Oral Health 15 (Suppl. 1):12. http://dx.doi.org/10.1186/1472-6831-15-S1-S12

Department of Health/British Association for the Study of Community Dentistry 2007. Delivering Better Oral Health: An Evidence-Based Toolkit for Prevention. 1st edn. London.

Hall-Scullin E, Whitehead H, Milsom KM, Tickle M, Su T-L, Walsh T. In press. Longitudinal study of caries development from childhood to adolescence. J Dent Res

Health \& Social Care Information Centre. 2015. NHS Dental Statistics England 2014/15. Leeds: Health \& Social Care Information Centre.

Holmes RD, Porter J, Devapal L, White DA. 2016. Patterns of care and service use amongst children in England, Wales and Northern Ireland 2013. Br Dent J 221:509 514.

Lader D, Chadwick B, Chestnutt I, Hawker R, Morris J, Nuttall N, et al. 2005. Children's Dental Health in the UK National Survey 2003. London: Office for National Statistics

Marinho VC, Worthington HV, Walsh T, Clarkson JE. 2013. Fluoride varnishes for preventing dental caries in children and adolescents. Cochrane Database Syst Rev 7 :CD002279. http://dx.doi.org/10.1002/14651858.cd002279.pub2

Marinho VCC, Higgins JPT, Sheiham A, Logan S. 2004. Combinations of topical fluoride (toothpastes,mouth rinses, gels, varnishes) versus single topical fluoride for preventing dental caries in children and adolescents. Cochrane Database Syst Rev $1:$ CD002781.

Marinho VCC, Higgins JPT, Logan S, Sheiham A. 2003. Fluoride toothpastes for preventing dental caries in children and adolescents. Cochrane Database Syst Rev 1 :CD002278. http://dx.doi.org/10.1002/14651858.cd002278 
Milsom KM, Blinkhorn AS, Tickle M. 2008. The incidence of dental caries in the primary molar teeth of young children receiving National Health Service funded dental care in practices in the North West of England. Br Dent J 205:E14. http://dx.doi.org/10.1038/sj.bdj.2008.582

Mitropoulos CM, Pitts NB, Deery C. 1992. British Association for the Study of Community Dentistry criteria for the standardised clinical assessment of dental health (1992/3). In: BASCD trainer's pack for caries prevalence studies 1992/3. Dundee: University of Dundee.

Northern Ireland Statistics \& Research Agency. 2010. Northern Ireland Multiple Deprivation Measure. Belfast.

O'Neil C, Worthington HV, Donaldson M, Birch S, Noble S, Killough S, Murphy L, Greer M, Brodison J, Tickle M. In press. Cost-effectiveness of caries prevention in practice: randomized controlled trial. J Dent Res.

Pitts N, Chadwick B, Anderson T. 2015. Children's Dental Health Survey 2013. Report 2: Dental Disease and Damage in Children England, Wales and Northern Ireland. Leeds: Health \& Social Care Information Centre.

Public Health England 2014. Delivering Better Oral Health: An Evidence-Based Toolkit for Prevention. 3rd edn. London.

Public Health England 2016 Children's Oral Health Improvement Programme Board $\begin{array}{lllll}\text { Action } & \text { Plan } & 2016 & - & 2020\end{array}$ https://www.gov.uk/government/uploads/system/uploads/attachment data/file/56532 5/action plan dental.pdf (accessed February 2017).

Ravaghi V, Hill K, Ryan R, Dennes M. 2015. Children's Dental Health Survey 2013. Country Specific Report: Northern Ireland. The Health and Social Care Information Centre. URL: www.hscic.gov.uk/catalogue/PUB17137/CDHS2013-Northern-IrelandReport.pdf (accessed August 2015).

Tickle M, Blinkhorn AS, Milsom KM. 2008. The occurrence of dental pain and extractions over a 3-year period in a cohort of children aged 3- 6 years. J Public Health Dent 68:63-69. http://dx.doi.org/10.1111/j.1752-7325.2007.00048.x 
Tickle M, Milsom KM, Donaldson M, Killough S, O’ Neill C, Crealey G, Sutton M, Noble S, Greer M, Worthington HV. 2011. Protocol for Northern Ireland Caries Prevention in Practice Trial (NIC-PIP) trial: a randomised controlled trial to measure the effects and costs of a dental caries prevention regime for young children attending primary care dental services. BMC Oral Health 11 :27. http://dx.doi.org/10.1186/1472-6831-11-27

Tickle M, O' Neill C, Donaldson M, Birch S, Noble S, Killough S, Murphy L, Greer M, Brodison J, Verghis $\mathrm{R}$ et al. 2016. A randomised controlled trial to measure the effects and costs of a dental caries prevention regime for young children attending primary care dental services: the Northern Ireland Caries Prevention In Practice (NIC-PIP) trial. Health Technol Assess 20 (71). 
Table 1. Baseline demographic data for all recruited children by study group

\begin{tabular}{|c|c|c|c|}
\hline & $\begin{array}{l}\text { Intervention Group } \\
(\mathrm{N}=624)\end{array}$ & $\begin{array}{l}\text { Control Group } \\
(\mathrm{N}=624)\end{array}$ & $\begin{array}{l}\text { Total } \\
(\mathrm{N}=1248)\end{array}$ \\
\hline \multicolumn{4}{|l|}{ Gender } \\
\hline Male & $283(45.4 \%)$ & $296(47.4 \%)$ & $597(46.4 \%)$ \\
\hline Female & $341(54.7 \%)$ & $328(52.6 \%)$ & $669(53.6 \%)$ \\
\hline \multicolumn{4}{|l|}{ Age (years) } \\
\hline Mean (s.d) & $3.1(0.53)$ & $3.1(0.53)$ & $3.1(0.53)$ \\
\hline $\begin{array}{l}\text { Median (minimum, } \\
\text { maximum) }\end{array}$ & $3.1(2.0,4.0)$ & $3.0(2.0,4.0)$ & $3.1(2.0,4.0)$ \\
\hline Missing & 0 & 0 & 0 \\
\hline \multicolumn{4}{|l|}{ MDM } \\
\hline $\begin{array}{ll}\text { Quintile } 1 & \text { (most } \\
\text { deprived) } & \end{array}$ & $88(14.1 \%)$ & $106(17.0 \%)$ & $194(15.6 \%)$ \\
\hline Quintile 2 & $141(22.6 \%)$ & $134(21.5 \%)$ & $275(22.1 \%)$ \\
\hline Quintile 3 & $172(27.6 \%)$ & $155(24.9 \%)$ & $327(26.4 \%)$ \\
\hline Quintile 4 & $148(23.8 \%)$ & $155(24.9 \%)$ & $303(24.3 \%)$ \\
\hline $\begin{array}{l}\text { Quintile } 5 \text { (least } \\
\text { deprived) }\end{array}$ & $74(11.9 \%)$ & $73(11.7 \%)$ & $147(11.8 \%)$ \\
\hline Missing & 1 & 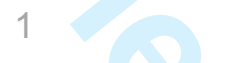 & 2 \\
\hline
\end{tabular}

http://mc.manuscriptcentral.com/jdr 
Table 2. Descriptive data for binary variables: conversion of caries free children to caries active children, how many of these children had teeth extracted and how many had toothache over three years

\begin{tabular}{|c|c|c|c|c|}
\hline All Children & $\begin{array}{c}\text { Intervention } \\
\text { Group } \\
(n=549)\end{array}$ & $\begin{array}{l}\text { Control } \\
\text { Group } \\
(n=547)\end{array}$ & $\begin{array}{c}\text { Total } \\
(n=1096)\end{array}$ & $\begin{array}{r}\text { Difference in } \\
\text { percentages } \\
\text { \{Control - } \\
\text { Intervention; } \\
\text { unadjusted }\} \\
(95 \% \mathrm{Cl})\end{array}$ \\
\hline $\begin{array}{l}\text { Number of children } \\
\text { becoming caries active }\end{array}$ & $187(34.1 \%)$ & $213(38.9 \%)$ & $400(36.5 \%)$ & $4.9(-0.8 \%$ to $10.6 \%)$ \\
\hline $\begin{array}{l}\text { Number of children with } \\
\text { toothache }\end{array}$ & $106(19.3 \%)$ & $120(21.9 \%)$ & $226(20.6 \%)$ & $2.6(-2.2 \%$ to $7.4 \%)$ \\
\hline $\begin{array}{l}\text { Children who } \\
\text { developed caries }\end{array}$ & $\begin{array}{c}\text { Intervention } \\
\text { Group } \\
(n=187)\end{array}$ & $\begin{array}{l}\text { Control } \\
\text { Group } \\
(n=213)\end{array}$ & $\begin{array}{c}\text { Total } \\
(n=400)\end{array}$ & $\begin{array}{r}\text { Difference in } \\
\text { percentages } \\
\text { \{Control - } \\
\text { Intervention; } \\
\text { unadjusted } \\
(95 \% \mathrm{Cl})\end{array}$ \\
\hline $\begin{array}{l}\text { Number of children with } \\
\text { toothache }\end{array}$ & $69(36.9 \%)$ & $95(44.6 \%)$ & $164(41.0 \%)$ & $7.7(-1.9 \%$ to $17.3 \%)$ \\
\hline $\begin{array}{l}\text { Number of children who } \\
\text { had teeth extracted }\end{array}$ & $21(11.2 \%)$ & $28(13.1 \%)$ & $49(12.3 \%)$ & $1.9(-4.5 \%$ to $8.3 \%)$ \\
\hline
\end{tabular}


Table 3. Outcomes from trial: adjusted and unadjusted effect estimates for the comparison between intervention and control groups.

\begin{tabular}{|c|c|c|c|}
\hline \multirow{4}{*}{$\begin{array}{l}\text { Outcome } \\
\text { Caries active } \\
\text { or not }\end{array}$} & \multicolumn{2}{|l|}{ Effect estimate $(95 \% \mathrm{Cl})$} & \multirow{2}{*}{$\begin{array}{l}\text { P-Value } \\
0.11\end{array}$} \\
\hline & $\begin{array}{l}\text { Odds Ratio (adjusted for } \\
\text { gender, MDM) }\end{array}$ & 0.81 (0.64 to 1.04$)$ & \\
\hline & Odds Ratio (unadjusted) & $0.81(0.63$ to 1.04$)$ & 0.09 \\
\hline & $\begin{array}{l}\text { Odds ratio (adjusted for } \\
\text { gender, MDM, practice) }\end{array}$ & $0.81(0.64$ to 1.04$)$ & 0.10 \\
\hline $\begin{array}{l}\text { dmfs } \\
\text { (children with } \\
\text { caries) }\end{array}$ & $\begin{array}{l}\text { Mean difference (adjusted } \\
\text { for gender, MDM) }\end{array}$ & $-2.29(-3.96$ to -0.63$)$ & 0.007 \\
\hline $\begin{array}{l}\text { Episodes of } \\
\text { pain }\end{array}$ & $\begin{array}{l}\text { Regression } \\
\text { from negative } \\
\text { (adjusted for ginomial } \\
\text { MDM) }\end{array}$ & $-0.03(-0.32$ to 0.25$)$ & 0.81 \\
\hline $\begin{array}{l}\text { Number of } \\
\text { extracted } \\
\text { teeth } \\
\text { (children with } \\
\text { caries) } \\
\end{array}$ & $\begin{array}{l}\text { Regression } \\
\text { from negative binomial } \\
\text { (adjusted for gender, } \\
\text { MDM) }\end{array}$ & $-0.03(-0.88$ to 0.82$)$ & 0.95 \\
\hline $\begin{array}{l}\text { Number of } \\
\text { Serious } \\
\text { Adverse } \\
\text { Events } \\
\text { (SAEs) } \\
\end{array}$ & $\begin{array}{l}\text { Regression } \\
\text { from negative } \\
\text { (adjusted for } \text { binomial } \\
\text { MDM) }\end{array}$ & $-0.19(-0.27$ to 0.65$)$ & 0.42 \\
\hline
\end{tabular}


Table 4. Descriptive data for discrete variables: number of caries surfaces, number of teeth extracted and number of episodes of pain in children with caries at three years.

\begin{tabular}{|l|l|l|l|}
\hline $\begin{array}{l}\text { Discrete } \\
\text { variable }\end{array}$ & $\begin{array}{l}\text { Intervention } \\
\text { Group } \\
(\mathrm{n}=187)\end{array}$ & $\begin{array}{l}\text { Control Group } \\
(\mathrm{n}=213)\end{array}$ & $\begin{array}{l}\text { Mean difference } \\
(95 \% \mathrm{Cl})\end{array}$ \\
\hline Mmfs & $7.18(7.99)$ & $9.61(8.75)$ & $-2.43(-4.08$ to -0.77$)$ \\
\hline $\mathrm{mt}$ & $0.45(1.43)$ & $0.46(1.44)$ & $0.001(-0.28$ to 0.28) \\
\hline $\begin{array}{l}\text { number of } \\
\text { episodes of } \\
\text { pain in children } \\
\text { with caries }\end{array}$ & $0.85(1.41)$ & $1.08(1.60)$ & $-0.23(-0.53$ to 0.07) \\
\hline
\end{tabular}




\title{
Figure 1: CONSORT Flow Chart
}

\section{Journal of Dental Research}

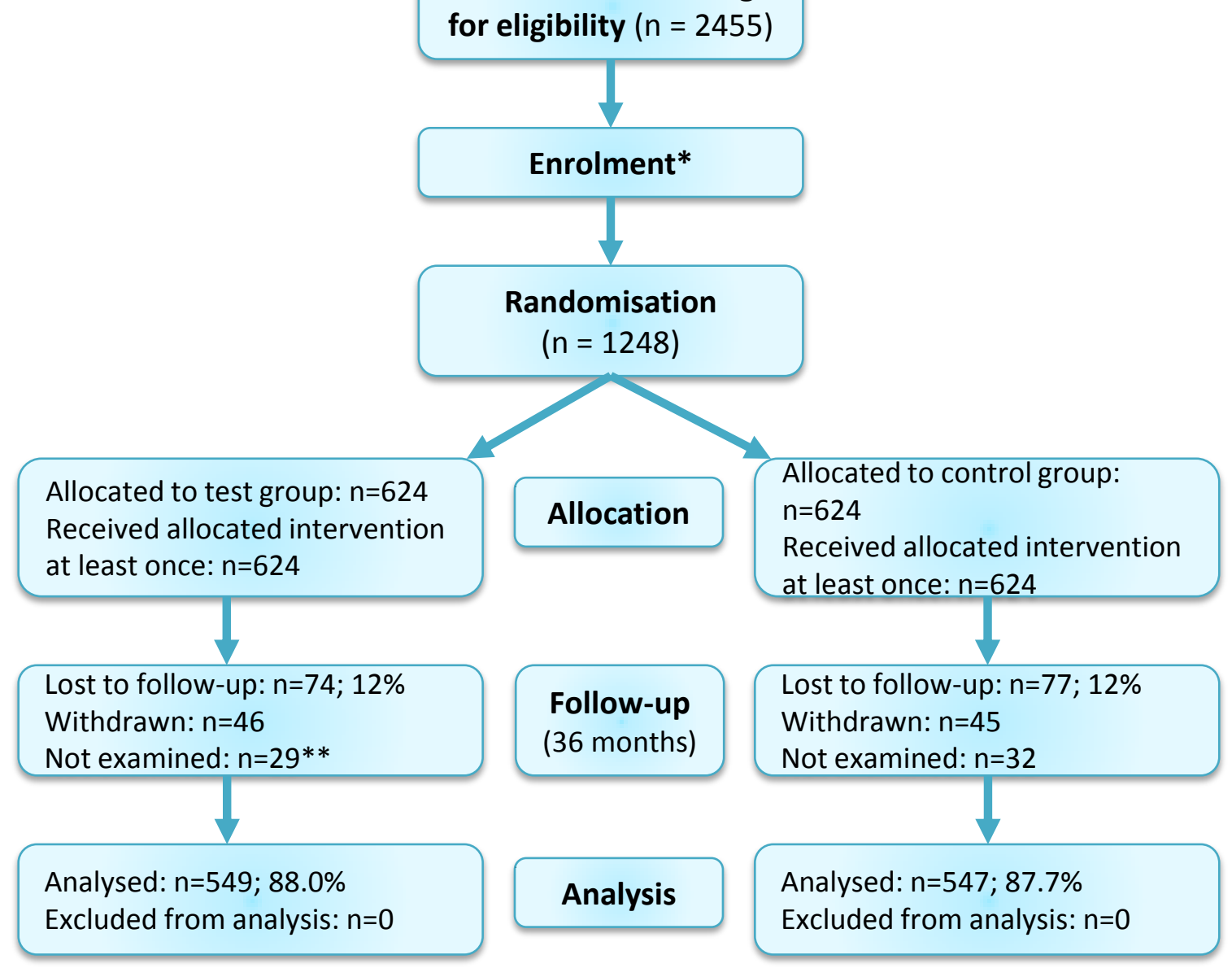

* Not randomised n=1207 (49.2\%)

- $\quad$ CDS assessor refusal (36)

- $\quad$ Parent withheld consent (138)

- $\quad$ Did not attend ( $n=758)$

- Ineligible (158): caries (85), age (35), allergies (22), hospitalisation (10), adverse medical history (2), other trial (2), history lactose intolerant (1), not known (1)

- $\quad$ Other reasons (117): patient would no cooperate (64), sibling recruited (16), appointment cancelled (15), parent absent (11), already on trial (3), language barrier (3), family migrating (2), patient sick (2), family left due to appointment (1)

\author{
http://mc.manuscriptcentral.com/jdr
}

** One child attended but did not have caries exam 


\section{On line appendix}

Title: A randomized controlled trial of caries prevention in dental practice

M Tickle, C O'Neill, M Donaldson, S Birch, S Noble, S Killough, L Murphy, M Greer, J Brodison, R Verghis, HV Worthington

Appendix Table 1. Results calibration prior to outcome assessment: surfaces - kappa statistics and asymptotic standard errors in parenthesis for a) inter -examiner agreement (first visit) and b) intra-examiner agreement (both visits) is shown on the diagonal, for surfaces (25 children; 2200 surfaces at first exam)

\begin{tabular}{|l|l|l|l|l|l|l|l|l|l|l|l|l|l|}
\hline & $1^{*}$ & 2 & 3 & 4 & 5 & 6 & 7 & 8 & 9 & 10 & 11 & 12 \\
\hline 1 & $0.947^{* *}$ & 0.891 & 0.827 & 0.863 & 0.902 & 0.819 & 0.874 & 0.793 & 0.831 & 0.894 & 0.864 & 0.851 & 0.881 \\
& $(0.013)$ & $(0.018)$ & $(0.023)$ & $(0.020)$ & $(0.017)$ & $(0.022)$ & $(0.018)$ & $(0.022)$ & $(0.022)$ & $(0.017)$ & $(0.019)$ & $(0.020)$ & $(0.018)$ \\
\hline 2 & & 0.919 & 0.857 & 0.886 & 0.890 & 0.817 & 0.868 & 0.807 & 0.810 & 0.858 & 0.904 & 0.834 & 0.881 \\
& & $(0.016)$ & $(0.021)$ & $(0.018)$ & $(0.018)$ & $(0.022)$ & $(0.019)$ & $(0.022)$ & $(0.024)$ & $(0.020)$ & $(0.016)$ & $(0.021)$ & $(0.018)$ \\
\hline 3 & & & 0.889 & 0.809 & 0.856 & 0.790 & 0.771 & 0.737 & 0.805 & 0.837 & 0.801 & 0.756 & 0.824 \\
& & & $(0.019)$ & $(0.024)$ & $(0.021)$ & $(0.025)$ & $(0.025)$ & $(0.025)$ & $(0.025)$ & $(0.022)$ & $(0.024)$ & $(0.025)$ & $(0.023)$ \\
\hline 4 & & & & 0.925 & 0.856 & 0.787 & 0.858 & 0.819 & 0.801 & 0.843 & 0.883 & 0.846 & 0.848 \\
& & & & 0.016 & $(0.020)$ & $(0.023)$ & $(0.019)$ & $(0.021)$ & $(0.024)$ & $(0.021)$ & $(0.018)$ & $(0.020)$ & $(0.020)$ \\
\hline 5 & & & & & 0.955 & 0.838 & 0.861 & 0.790 & 0.884 & 0.899 & 0.857 & 0.838 & 0.892 \\
& & & & & $(0.012)$ & $(0.021)$ & $(0.019)$ & $(0.023)$ & $(0.019)$ & $(0.017)$ & $(0.020)$ & $(0.021)$ & $(0.018)$ \\
\hline 6 & & & & & & 0.870 & 0.805 & 0.786 & 0.795 & 0.822 & 0.816 & 0.801 & 0.821 \\
& & & & & & $(0.019$ & $(0.022)$ & $(0.022)$ & $(0.025)$ & $(0.021)$ & $(0.021)$ & $(0.022)$ \\
$(0.021)$
\end{tabular}




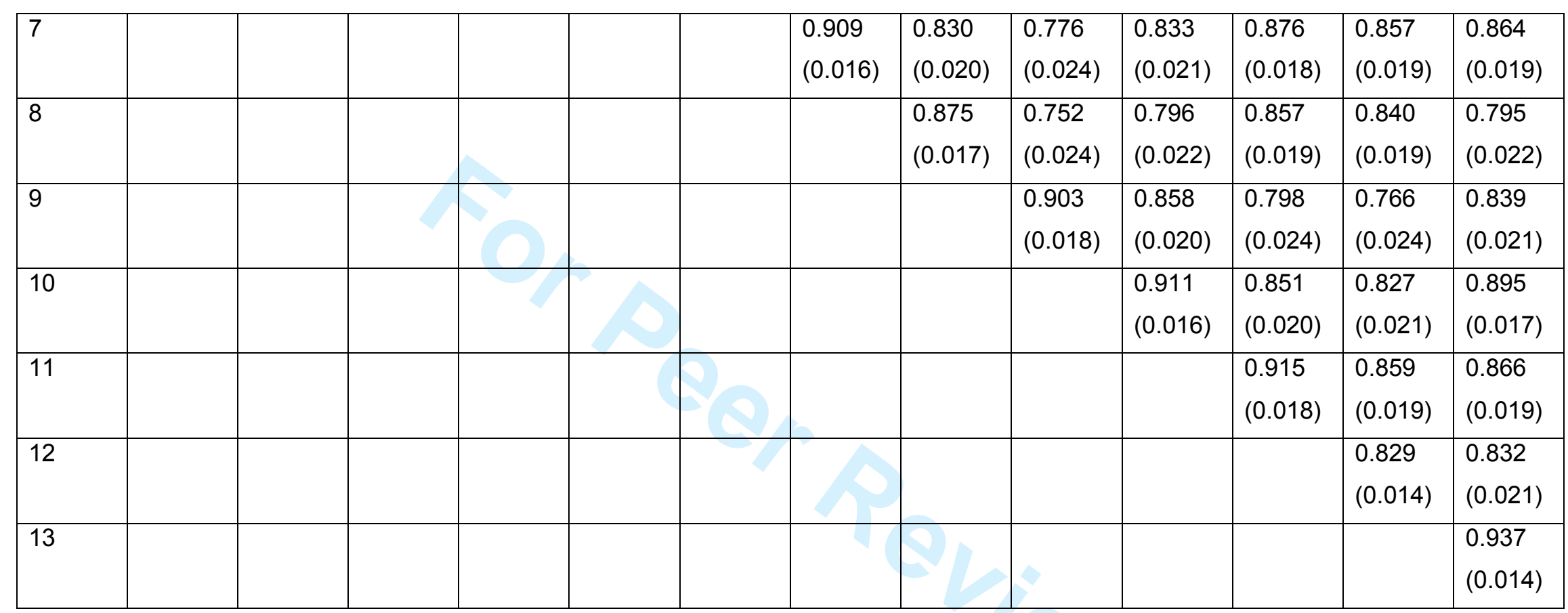

${ }^{*}$ Gold Standard Examiner number 1

**Intra-examiner kappas highlighted in blue 
Appendix Table 2. The causes of the 100 reported Serious Adverse Events (SAEs) by study group

\begin{tabular}{|l|l|l|l|}
\hline $\begin{array}{l}\text { Serious Adverse } \\
\text { Events category }\end{array}$ & Intervention Group & $\begin{array}{l}\text { Control } \\
\text { Group }\end{array}$ & Total \\
\hline Cardiac disorders & 4 & 1 & 5 \\
\hline $\begin{array}{l}\text { Gastrointestinal } \\
\text { disorders }\end{array}$ & 4 & 5 & 9 \\
\hline $\begin{array}{l}\text { General disorders and } \\
\text { administration site } \\
\text { conditions| }\end{array}$ & 5 & 7 & 12 \\
\hline $\begin{array}{l}\text { Infections and } \\
\text { infestations }\end{array}$ & 13 & 9 & 22 \\
\hline $\begin{array}{l}\text { Metabolism and } \\
\text { nutrition disorders }\end{array}$ & 1 & 0 & 1 \\
\hline $\begin{array}{l}\text { Musculoskeletal and } \\
\text { connective tissue } \\
\text { disorders }\end{array}$ & 7 & 4 & 11 \\
\hline $\begin{array}{l}\text { Renal and urinary } \\
\text { disorders }\end{array}$ & 1 & 0 & 1 \\
\hline $\begin{array}{l}\text { Respiratory, thoracic } \\
\text { and mediastinal } \\
\text { disorders }\end{array}$ & 10 & 12 & 22 \\
\hline $\begin{array}{l}\text { Skin and subcutaneous } \\
\text { tissue disorders }\end{array}$ & 1 & 1 & 100 \\
\hline $\begin{array}{l}\text { Surgical and medical } \\
\text { procedures }\end{array}$ & 9 & 6 & 2 \\
\hline Total & $\mathbf{5 5}$ & $\mathbf{4 5}$ & \\
\hline
\end{tabular}

A logistic regression model for a child having an SAE or not, estimating the difference between the study groups, adjusted for age and MDM quintile was not statistically significant $\mathrm{OR} 1.23(95 \% \mathrm{Cl} 0.79$ to $1.94 ; \mathrm{P}=0.36)$. The negative binomial model for the number of SAEs, which indicated significant over-dispersion, was also not statistically significant (regression coefficient $0.1995 \% \mathrm{Cl}-0.27$ to $0.65 ; \mathrm{P}=0.42$ ). $\mathrm{A}$ 
further 10 children in the intervention group had Adverse ReactionslUnexpected Adverse Reactions of a minor nature which were considered to be related to the treatment (4 gastointestinal disorders, 5 general disorders and administration site conditions, and 1 skin and subcutaneous tissue disorders). 
Appendix Figure 1. Comparison of the socio-economic profile (measured by proportions of the population in quintiles of deprivation measured using the Multiple Deprivation Measure 2010) of the total population of 2-3 years olds in Northern Ireland, the population of 2-3 year olds registered with a NHS dentist in Northern Ireland and the population recruited to the NIC PIP trial at baseline.

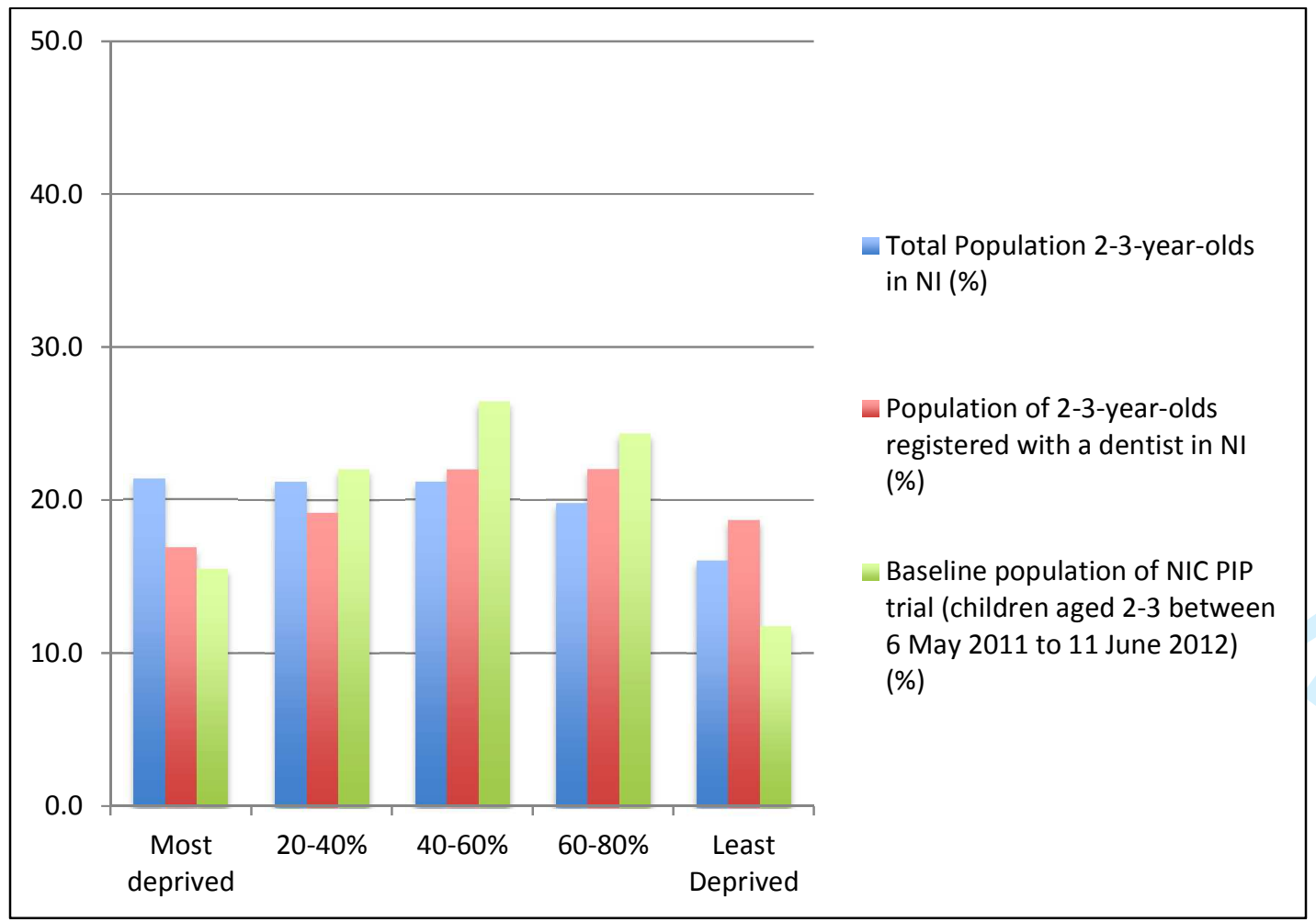

http://mc.manuscriptcentral.com/jdr 
Appendix: Evidence-based, standardised parental advice sheet

6. For children aged 0-3 years apply a SMEAR of toothpaste

7. For children aged 3-7 years apply a PEA-SIZED amount of toothpaste

8. After brushing don't rinse - encourage your child to spit out excess toothpaste. (Try to avoid swallowing)

9. Don't allow children to lick or eat toothpaste from the tube (keep out of reach)

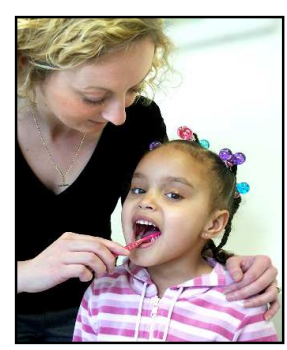

5. Use toothpaste containing no less than 1000 parts per million (ppm) fluoride. (This information should appear on the packaging)

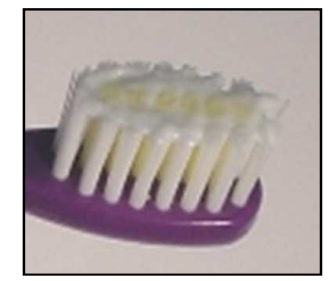

\section{Dietary Advice}

1. Limit the eating of sugary foods and drinks to mealtimes and no more than $4 \times$ per day.

2. Avoid eating sugary foods and drinks before bedtime

3. Always ask for sugar free medicines

\section{Dental Visits}

1. Children should visit the dentist approximately every 6 months or as often as their dentist advises. 


\section{CONSORT 2010 checklist of information to include when reporting a randomised trial*}

\begin{tabular}{|c|c|c|}
\hline Section/Topic & $\begin{array}{c}\text { Item } \\
\text { No }\end{array}$ & Checklist item \\
\hline \multicolumn{3}{|l|}{ Title and abstract } \\
\hline & $1 a$ & Identification as a randomised trial in the title \\
\hline & $1 \mathrm{~b}$ & Structured summary of trial design, methods, results, and conclusions (for specific guidance see CONSORT for abstracts) \\
\hline \multicolumn{3}{|l|}{ Introduction } \\
\hline Background and & $2 a$ & Scientific background and explanation of rationale \\
\hline objectives & $2 b$ & Specific objectives or hypotheses \\
\hline
\end{tabular}

\section{Methods}

Trial design

3a Description of trial design (such as parallel, factorial) including allocation ratio

Participants

$3 b$

Important changes to methods after trial commencement (such as eligibility criteria), with reasons

4a Eligibility criteria for participants

$4 \mathrm{~b} \quad$ Settings and locations where the data were collected

Interventions

The interventions for each group with sufficient details to allow replication, including how and when they were actually administered

Outcomes

$6 a$

Completely defined pre-specified primary and secondary outcome measures, including how and when they were assessed

Sample size

$6 \mathrm{~b}$ Any changes to trial outcomes after the trial commenced, with reasons

7a How sample size was determined

$7 \mathrm{~b}$ When applicable, explanation of any interim analyses and stopping guidelines

Reported on page No

\section{Randomisation:}

Sequence generation

Allocation concealment mechanism Implementation

8a Method used to generate the random allocation sequence

$8 \mathrm{~b}$ Type of randomisation; details of any restriction (such as blocking and block size)

9 Mechanism used to implement the random allocation sequence (such as sequentially numbered containers), describing any steps taken to conceal the sequence until interventions were assigned

10 Who generated the random allocation sequence, who enrolled participants, and who assigned participants to interventions

Blinding

11a If done, who was blinded after assignment to interventions (for example, participants, care providers, those

1

2

3

3

\begin{tabular}{l}
$\frac{4}{4}$ \\
\hline 4 \\
\hline $4-5$ \\
\hline 5
\end{tabular}

4-5

\begin{tabular}{l}
\hline 5 \\
\hline $5-6$ \\
\hline$N \backslash A$ \\
\hline
\end{tabular}

$\frac{4}{4}$

4

4 


\section{assessing outcomes) and how}

11b If relevant, description of the similarity of interventions

Statistical methods

\section{Results}

Participant flow (a diagram is strongly recommended)

Recruitment

Baseline data

Numbers analysed

Outcomes and

estimation

Ancillary analyses

Harms

\section{Discussion}

Limitations

Generalisability

Interpretation

Other information

Registration

Protocol

$13 a$ were analysed for the primary outcome

$14 \mathrm{~b}$ Why the trial ended or was stopped by original assigned groups precision (such as $95 \%$ confidence interval) pre-specified from exploratory

23 Registration number and name of trial registry
For each group, the numbers of participants who were randomly assigned, received intended treatment, and

$13 \mathrm{~b}$ For each group, losses and exclusions after randomisation, together with reasons

14a Dates defining the periods of recruitment and follow-up

15 A table showing baseline demographic and clinical characteristics for each group

16 For each group, number of participants (denominator) included in each analysis and whether the analysis was

17a For each primary and secondary outcome, results for each group, and the estimated effect size and its

$17 \mathrm{~b}$ For binary outcomes, presentation of both absolute and relative effect sizes is recommended

18 Results of any other analyses performed, including subgroup analyses and adjusted analyses, distinguishing

19 All important harms or unintended effects in each group (for specific guidance see CONSORT for harms)

20 Trial limitations, addressing sources of potential bias, imprecision, and, if relevant, multiplicity of analyses

21 Generalisability (external validity, applicability) of the trial findings

22 Interpretation consistent with results, balancing benefits and harms, and considering other relevant evidence

24 Where the full trial protocol can be accessed, if available

\begin{tabular}{l}
\hline 5 \\
\hline $5-6$ \\
\hline $5-6$ \\
\hline
\end{tabular}

$7 \&$ Fig 1

\begin{tabular}{l}
\hline $4 \& 7$ \\
\hline 7 \\
\hline 7 \\
\hline Table 1 \\
\hline
\end{tabular}

Tables 2,3,4

Tables 2,3,4

Tables 2,3

N\A

9 and

appendix

Table 2

10,11

10 and appendix

Figure 1

13

2

Reference

Tickle et al,

2011 
*We strongly recommend reading this statement in conjunction with the CONSORT 2010 Explanation and Elaboration for important clarifications on all the items. If relevant, we also recommend reading CONSORT extensions for cluster randomised trials, non-inferiority and equivalence trials, non-pharmacological treatments, herbal interventions, and pragmatic trials.

Additional extensions are forthcoming: for those and for up to date references relevant to this checklist, see www.consort-statement.org. 